\title{
ANÁLISE DE TRABALHOS APRESENTADOS NA ANPED (2004 A 2013) COM A TEMÁTICA DE GÊNERO E SEXUALIDADE NO ENSINO DAS CIÊNCIAS
}

Alexandre Gomes Soares ${ }^{1}$

Daniel Manzoni de Almeida ${ }^{2}$

\section{Resumo}

O tema gênero e sexualidade vem se delineando nas reuniões anuais da Associação Nacional de Pós-Graduação e Pesquisa em Educação (ANPEd), especificamente no Grupo de Trabalho 4 - Didática (GT 4) e no Grupo de Trabalho 23 - Gênero, Sexualidade e Educação (GT 23). O objetivo deste artigo é analisar e compreender como esses GTs vêm concebendo pesquisas que tratam dessa temática com foco no ensino de Ciências, nas reuniões anuais da ANPEd, no período de 2004 a 2013. A metodologia utilizada envolveu a identificação e a análise dos trabalhos publicados nos anais das reuniões e o levantamento do total de artigos publicados pelos GTs 4 e 23, destacando os que trazem propostas didáticas e análises sobre ensino de gênero e sexualidade no tocante ao ensino de Ciências. Concluímos em nossa análise uma reduzida abordagem científica das temáticas sobre gênero e sexualidade no contexto das práticas pedagógicas no universo do ensino de Ciências.

Palavras-chave: Gênero e sexualidade; Ensino de Ciências; ANPEd

\footnotetext{
${ }^{1}$ Mestre em Educação Tecnológica. Doutorando em Educação na Universidade de São Paulo. Endereço: Rua José Joaquim Duarte,147, Bloco Apto 401, Bairro Heliópolis, Belo Horizonte/ Minas Gerais, Brasil. CEP: 31.741-580. Endereço eletrônico: prof.alexhis@gmail.com

${ }^{2}$ Mestre e Doutor em Ciências Biologicas. Pós-Doutorando em Ensino de Biologia/Ciências. Faculdade de Educação, Universidade de São Paulo. Endereço; Endereço: Avenida da Universidade, 308 CEP: 05508-040, Cidade Universitária, São Paulo, Brasil. Endereço eletrônico: danielmanzoni@yahoo.com.br
} 


\section{INTRODUÇÃO}

[...] a pesquisa em Educação deve sempre buscar uma compreensão mais ampla sobre os processos interativos em sala de aula em suas múltiplas e complexas variáveis, não apenas aquelas relacionadas à dimensão cognitiva, mas também as que dizem respeito aos aspectos subjetivos e emocionais. O papel da escola na construção das identidades de gênero, numa sociedade ainda marcada por estereótipos que hierarquizam homens e mulheres no campo cognitivo, é uma dessas importantes variáveis. (Angela Maria F. L. Souza,2008)

A temática de gênero e sexualidade tem sido objeto de diferentes pesquisadores nos campos da Antropologia, Sociologia, Psicologia, das Ciências Sociais e da Educação. Neste último, as discussões têm se delineado de forma diversa. Assim, o presente trabalho identifica e analisa como o tema de gênero e sexualidade vem se configurando nas reuniões anuais da Associação Nacional de Pós-Graduação e Pesquisa em Educação (ANPEd), especificamente no Grupo de Trabalho 4 - Didática (GT 4) e no Grupo de Trabalho 23 - Gênero, Sexualidade e Educação (GT 23), no período de 2004 a 2013.

O objetivo é verificar como esses GTs vêm concebendo pesquisas que tratam da temática de gênero e sexualidade e sua inserção no ensino de Ciências, nas reuniões anuais da ANPEd. A escolha dos trabalhos dessa associação justifica-se pela relevância da instituição de pesquisa em educação do nosso país.

Para cumprir o objetivo proposto, a metodologia utilizada envolveu a identificação e a análise dos trabalhos publicados nos anais das reuniões, de 2004 a 2013, e o levantamento do total de artigos publicados nos anais pelos GTs 4 e 23, destacando os que trazem propostas didáticas e análises sobre ensino de gênero e sexualidade no ensino de Ciências. $\mathrm{Na}$ sequência, realizou-se a análise do conteúdo proposto com o objetivo de descrever a abordagem de pesquisa.

\section{OS MARCADORES SOCIAIS DE GÊNERO E SEXUALIDADE: NOTAS INTRODUTÓRIAS}

No Brasil, as discussões sobre direitos humanos, gênero, sexualidade e diversidade no cenário escolar ainda carregam visões e representações dogmáticas sobre o tema, dados que são apontados, por exemplo, na pesquisa denominada Diversidade Sexual e Homofobia no Brasil (2011), realizada pela Fundação Perseu Abramo em conjunto com a Fundação Rosa 
Luxemburg Stiftung (RLS) ${ }^{3}$. Entretanto, a participação dos movimentos sociais nos debates sobre cidadania - em especial dos movimentos feminista e de lésbicas, gays, bissexuais, transgêneros, travestis e intersexuais (LGBTTI) - e a preocupação da academia com essas categorias vêm se tornando visíveis, além das ações políticas.

Na busca por uma compreensão do contexto escolar, Sacristán (2000) destaca que as práticas educacionais são delineadas por um projeto seletivo de cultura, social, política e administrativamente condicionado, que preenche a atividade escolar e que se torna realidade dentro das condições da escola no âmbito curricular. Nesse sentido, surgiram algumas indagações: se os marcadores sociais de gênero e diversidade estão presentes na sociedade, quais abordagens essa temática tem na formação e atuação dos/as docentes, especialmente na educação básica? Como esse tema tem sido tratado no ensino de Ciências?

A partir dessas inquietações iniciais, buscou-se identificar a inserção do tema gênero e sexualidade nas produções direcionadas para a ANPEd.

Segundo $\operatorname{Scott}^{4}$ (1990, p. 86), “o gênero é um elemento constitutivo de relações sociais fundadas sobre as diferenças percebidas entre os sexos, [constituindo] um primeiro modo de dar significado às relações de poder”. Para Weeks (2009), a sexualidade é percebida numa perspectiva de três grandes forças: possibilidades biológicas, processos psicológicos e, em terceiro lugar, a parte que foi esquecida ou menosprezada, da história, da sociedade e da cultura. Diante dessas breves notas introdutórias, compreende-se esse campo numa perspectiva relacional e, assim, pensa-se em categorias não fixas.

Ainda nessa discussão, concorda-se com Carvalho (2010, p. 524), ao apontar

\footnotetext{
${ }^{3}$ Venturi (2010) destaca que no final de janeiro de 2009 foi apresentada no Fórum Social Mundial, em Belém, a primeira parte da pesquisa intitulada Diversidade Sexual e Homofobia no Brasil, Intolerância e respeito às diferenças sexuais - uma realização da Fundação Perseu Abramo, em parceria com a alemã Rosa Luxemburg Stiftung. Com dados coletados em junho de 2008(1), a pesquisa percorreu processo de elaboração semelhante ao de estudos anteriores do NOP(2), tendo sido convidados pela FPA para definir quais seriam as prioridades a investigar, entidades e pesquisadores dedicados ao combate e ao estudo da estigmatização e da discriminação dos indivíduos e grupos com identidades ou comportamentos sexuais que não correspondem aos preceitos da heteronormatividade dominante - lésbicas, gays, bissexuais, travestis e transexuais (LGBT). Venturi (2010) descreve que indagados sobre a existência ou não de preconceito contra as pessoas LGBT no Brasil, quase a totalidade das pessoas entrevistadas respondeu afirmativamente: acreditam que existe preconceito contra travestis $93 \%$ (para $73 \%$ muito, para $16 \%$ um pouco), contra transexuais $91 \%$ (respectivamente $71 \%$ e 17\%), contra gays $92 \%$ (70\% e 18\%), contra lésbicas $92 \%$ (69\% e 20\%) e, tão freqüente, mas um pouco menos intenso, 90\% acham que no Brasil há preconceito contra bissexuais (para 64\% muito, para 22\% um pouco). Mas perguntados se são preconceituosos, apenas $29 \%$ admitiram ter preconceito contra travestis (e só $12 \%$ muito), $28 \%$ contra transexuais (11\% muito), $27 \%$ contra lésbicas e bissexuais (10\% muito para ambos) e $26 \%$ contra gays (9\% muito). Disponível em: http://www.fpa.org.br/o-que-fazemos/pesquisas-de-opiniao-publica/pesquisasrealizadas/apresentacao-4> Acesso em: 25 Jun 2015.

${ }^{4}$ Historiadora estadunidense que tem influências de Jacques Derrida e Michel Foucault em suas produções teóricas.
} 
[...] os desafios de examinar os aspectos de gênero dessas problemáticas, sabendo que eles não as esgotam, [...] são indispensáveis, ao lado de outras categorias de análise como relações raciais e hierarquias socioeconômicas. Acredito que apenas esse movimento teórico-metodológico nos permitirá perceber a centralidade do conceito de gênero na análise do cotidiano escolar.

Não obstante, vale destacar que os Parâmetros Curriculares Nacionais (PCN), em 1997, propiciaram um olhar sobre a temática de orientação sexual e sexualidade numa perspectiva transversal, o que denota uma implicação importante na formação docente e em sua atuação no espaço escolar.

\section{A DISCUSSÃO DE GÊNERO E SEXUALIDADE NO GT 4 - DIDÁTICA}

Antes de adentrar o mapeamento dos trabalhos que mencionam o tema de gênero e sexualidade no GT 4, propõe-se uma breve abordagem sobre a didática. De acordo com os pesquisadores Pimenta, Fusari, Almeida e Franco (2013), a didática é concebida como área da pedagogia que estuda o fenômeno ensino. De forma mais detalhada, afirmam que

[...] sendo uma área da pedagogia, a didática tem no ensino seu objeto de investigação. Considerá-lo como uma prática educacional em situações historicamente situadas significa examiná-lo nos contextos sociais nos quais se efetiva - nas aulas e demais situações de ensino das diferentes áreas do conhecimento, nas escolas, nos sistemas de ensino, nas culturas, nas sociedades -, estabelecendo-se os nexos entre tais contextos. (PIMENTA et al., 2013, p. 144)

Além disso, as recentes transformações nos sistemas escolares, especialmente na área de formação de professores, configuram uma "explosão didática". Isto impacta numa ressignificação que aponta para um balanço do ensino como prática social, das pesquisas e das modificações que têm provocado na prática social de ensinar. Para os pesquisadores, há uma indagação necessária: em que medida os resultados das pesquisas têm propiciado a construção de novos saberes e engendrado novas práticas, com vistas a superar as situações de desigualdades sociais, culturais e humanas produzidas pelo ensino e pela escola?

Essa questão revela também outros desafios que se colocam hoje à didática e ao campo educacional no qual estamos inseridos. Nesse sentido, busca-se analisar o percurso da 
temática de gênero e sexualidade no GT 4, tendo em vista alguns desses desafios postos no processo de ensino e aprendizagem.

As pesquisas envolvendo gênero e sexualidade estiveram presentes no GT 4 em apenas algumas reuniões no período abordado (Reuniões de $30^{\circ}$ [2007], 35 ${ }^{\circ}$ [2012], $36^{\circ}$ [2013]) (Tabela 1).

Do total de 142 trabalhos apresentados no recorte delimitado, três envolviam a temática de gênero e sexualidade, isto é, apenas 2,11\%. Apesar disso, a presença reduzida do tema nas reuniões não significa que não foi alvo de discussão, uma vez que pode ter sido direcionado para outros grupos de trabalho.

\section{Tabela 1.}

\section{Trabalhos do GT 4 publicados nos anais das reuniões da ANPED}

(2004 a 2013)

\begin{tabular}{|c|c|c|}
\hline Reuniões Anuais ANPEd /Ano & $\begin{array}{c}\text { Total de } \\
\text { Trabalhos }\end{array}$ & $\begin{array}{c}\text { Trabalhos } \\
\text { envolvendo a } \\
\text { temática de gênero e } \\
\text { sexualidade }\end{array}$ \\
\hline $27^{\mathrm{a}} / 2004$ & 14 & 0 \\
\hline $28 \mathrm{a} / 2005$ & 13 & 0 \\
\hline $29^{a} / 2006$ & 13 & 0 \\
\hline $30^{\mathrm{a}} / 2007$ & 16 & 1 \\
\hline $31^{\mathrm{a}} / 2008$ & 18 & 0 \\
\hline $32^{a} / 2009$ & 12 & 0 \\
\hline $33^{\mathrm{a}} / 2010$ & 13 & 0 \\
\hline $34^{\mathrm{a}} / 2011$ & 13 & 0 \\
\hline $35^{\mathrm{a}} / 2012$ & 21 & 1 \\
\hline $36^{a} / 2013$ & 9 & 1 \\
\hline Total & 142 & 3 \\
\hline
\end{tabular}

Na Tabela 2, nota-se que os trabalhos que abordam a temática de gênero e sexualidade versam sobre os mais variados recortes; porém, cabe salientar que apenas a leitura dos títulos dos trabalhos não permite verificar a diversidade de abordagens. Tal objetivo será demonstrado no item das análises. 
TABELA 2

Trabalhos submetidos as reuniões anuais da ANPEd no período de 2004 a 2013 com focos em gênero e diversidade sexual nos GT de Didática

\begin{tabular}{|c|c|c|c|}
\hline & $\begin{array}{l}\text { Reuniões } \\
\text { Anuais } \\
\text { ANPEd } \\
\text { /Ano }\end{array}$ & Títulos & Autor(a) \\
\hline \multirow[t]{2}{*}{1} & $30^{\mathrm{a}} / 2007$ & $\begin{array}{l}\text { Investigar a ação docente frente às diferenças, operando com a } \\
\text { noção de jurisprudência pedagógica }\end{array}$ & Cláudia Hernandez Barreiros \\
\hline & $35^{\mathrm{a}} / 2012$ & $\begin{array}{l}\text { 'Aponte o lápis, cole os bilhetes'... 'sim, professora!': a } \\
\text { socialização entre alunos estagiários e professoras em exercício }\end{array}$ & Márcia Regina do N. Sambugari \\
\hline \multicolumn{4}{|l|}{2} \\
\hline 3 & $36^{a} / 2013$ & $\begin{array}{l}\text { O reconhecimento para além da igualdade: subsídios para uma } \\
\text { educação intercultural }\end{array}$ & Kaé Stoll Colvero \\
\hline
\end{tabular}

Fonte: Elaborada a partir de informações contidas nas reuniões anuais da ANPEd (2004-2013). Disponível em : <http://www.anped.org.br/internas/ver/reunioes-anuais>. Acesso em :25 maio 2015.

\section{A DISCUSSÃO DE GÊNERO E SEXUALIDADE NO GT 23 - GÊNERO, SEXUALIDADE E EDUCAÇÃO}

A constituição do campo de gênero, sexualidade e educação como grupo de trabalho na ANPEd ocorreu em 2004; mas, bem antes disso, no final da década de 1970, já era notória toda uma produção acadêmica sobre o assunto. Meyer et al. (2004) destacam a impossibilidade de ignorar as relações de gênero e sexualidade quando se busca analisar e compreender questões sociais e educacionais.

Considerando a relevância da produção científica nesse campo, foram mapeados os trabalhos submetidos nas reuniões desse GT (Tabela 3).

\section{TABELA 3}

Trabalhos submetidos as reuniões anuais da ANPEd no período de 2004 a 2013 com focos em práticas de ensino gênero e sexualidade nos GT 23 - Gênero, Sexualidade e Educação

\begin{tabular}{ccc}
\hline Reuniões Anuais ANPEd /Ano & Trabalhos/Tema* & Trabalhos/Geral \\
\hline $27^{\mathrm{a}} / 2004$ & 0 & 13
\end{tabular}


SOARES, A. G.; ALMEIDA, D. M.

$\begin{array}{ccc}28^{\mathrm{a}} / 2005 & 0 & 13 \\ 29^{\mathrm{a}} / 2006 & 0 & 12 \\ 30^{\mathrm{a}} / 2007 & 0 & 16 \\ 31^{\mathrm{a}} / 2008 & 2 & 11 \\ 32^{\mathrm{a}} / 2009 & 0 & 12 \\ 33^{\mathrm{a}} / 2010 & 1 & 15 \\ 34^{\mathrm{a}} / 2011 & 0 & 13 \\ 35^{\mathrm{a}} / 2012 & 0 & 17 \\ 36^{\mathrm{a}} / 2013 & 0 & 17 \\ \text { Total } & \mathbf{3} & \mathbf{1 3 9}\end{array}$

Fonte: Elaborada a partir de informações contidas nas reuniões anuais da ANPEd (2004-2013). Disponível em: <http://www.anped.org.br/internas/ver/reunioes-anuais>. Acesso em :25 maio 2015.

A leitura das tabelas indica a reduzida presença de discussões de temática de gênero e sexualidade que abordem as disciplinas curriculares e especialmente o ensino de Ciências. Além disso, denota a necessidade de apropriação desse debate na construção do conhecimento e a constituição dos sujeitos enquanto produtores de identidade, saberes e ciência.

$\mathrm{Na}$ Tabela 4, ficam evidenciadas as experiências de pesquisas que foram objeto do recorte aqui proposto.

\section{TABELA 4}

Trabalhos submetidos as reuniões anuais da ANPEd no período de 2004 a 2013 com focos em gênero e diversidade sexual nos GT de Gênero, Sexualidade e Educação

\begin{tabular}{|c|c|c|c|}
\hline & $\begin{array}{l}\text { Reuniões } \\
\text { Anuais } \\
\text { ANPEd } \\
\text { /Ano } \\
\end{array}$ & Títulos & Autor(a) \\
\hline 1 & $31^{\mathrm{a} / 2008}$ & Quatro intervenções de uma pedagogia Queer & Maria Rita de Assis César \\
\hline & $31^{\mathrm{a} / 2008}$ & $\begin{array}{l}\text { Professores (as), sexualidade e educação sexual: produzindo } \\
\text { sujeitos nos contextos do programa afetivo-sexual }\end{array}$ & Roney Polato de Castro \\
\hline 3 & $33^{\mathrm{a}} / 2010$ & $\begin{array}{c}\text { Das noções de corpo no ensino de biologia aos dizeres sobre } \\
\text { sexualidade }\end{array}$ & $\begin{array}{c}\text { Elenita Pinheiro de Queiroz Silva - } \\
\text { Graça Aparecida Cicillini }\end{array}$ \\
\hline
\end{tabular}

Fonte: Elaborada a partir de informações contidas nas reuniões anuais da ANPEd (2004-2013). Disponível em: <http://www.anped.org.br/internas/ver/reunioes-anuais>. Acesso em :25 maio 2015.

\section{METODOLOGIA}


Seguindo o objetivo de realizar um levantamento das pesquisas com propostas didáticas e análises sobre ensino de gênero e sexualidade nas aulas de Ciências, foram identificados trabalhos com essas características submetidos em GTs de Didática (por comportar as temáticas que envolvem ensino [de Ciências] das reuniões) e Gênero, Sexualidade e Educação (por contemplar os artigos relacionados aos temas de gênero e sexualidade) entre 2004 a 2013 nos anais das reuniões anuais ANPEd.

A identificação desses artigos foi feita por meio de busca aos anais das reuniões da ANPEd ${ }^{5}$, com o cruzamento das seguintes palavras-chaves: "ensino de ciências", "gênero", "sexualidade", "gênero e sexualidade". Após o levantamento dos dados, os artigos encontrados foram selecionados e analisados.

\section{ANÁLISES}

Primeiramente a análise foi focada no GT de Didática. Do total de 142 trabalhos levantados, foram localizados três relacionados ao tema de sexualidade e gênero, pelo cruzamento de palavras-chaves (Tabela 1):

1) "Investigar a ação docente frente às diferenças, operando com a noção de jurisprudência pedagógica" (BARRETO, 2007). A autora traz como objeto de pesquisa os saberes docentes desenvolvidos no enfrentamento da diferença em sala de aula e realiza uma análise dos dados na fecundidade da noção de jurisprudência da pedagogia.

2) “Aponte o lápis, cole os bilhetes"... 'Sim, professora!': a socialização entre alunos estagiários e professoras em exercícios" (SAMBUGARI, 2012). A autora traz a discussão da análise de seu objeto de pesquisa, o estágio curricular no curso de Pedagogia, tendo como questão central a tensão da formação dos futuros professores em um percurso anterior, durante o qual já adquiriram modos de pensar e apreciar o exercício docente como alunos em toda a vida familiar, escolar e social, em detrimento do que vão experienciar nas salas de aula do estágio. A análise dos resultados, pela autora, mostraram que

\footnotetext{
${ }^{5}$ Disponível em: <http://www.anped.org.br/internas/ver/reunioes-anuais>. Acesso em: abr. 2015. 
[...] o quanto os percursos de cada um marcam suas vidas, traduzindo modos de pensar e agir a partir dessas vivencias, provocando diversidade na socialização, ainda que com certa regularidade, advindas dessas características sociais e pessoais. (SAMBUGARI, 2012, p.1)

Como conclusão, a autora apresenta que as ideias e informações sobre a docência transmitidas pelas professoras aos futuros professores provocaram diversas reações.

3) “O reconhecimento para além da igualdade: subsídios para a educação intercultural" (COLVERO, 2013). Trata-se de um ensaio teórico sobre o cotidiano escolar e a diferença que a ele é intrínseca, partindo do pressuposto de que um dos maiores desafios da escola hoje é fazer a articulação entre igualdade e diferença, sem que uma anule a outra. Assim, o autor coloca que

à luz da interculturalidade e de questões filosóficas, problematizo inicialmente a concepção pedagógica moderna que promove impositivamente o apagamento da alteridade dos sujeitos por meio da homogeneização, para, posteriormente, trazer considerações sobre a construção do discurso da diferença no campo pedagógico brasileiro. (COLVERO, 2013, p.1)

A segunda parte da análise focou o GT de Gênero, Sexualidade e Educação. Do total de 139 trabalhos levantados, foram localizados três relacionados ao tema, com o cruzamento de palavras-chaves (Tabela 2 ):

1) "Quatro intervenções de uma pedagogia Queer" (CESAR, 2008). A autora traz os resultados de uma pesquisa realizada em cinco escolas municipais e oito estaduais da cidade de Curitiba, sobre o discurso da sexualidade nas escolas.

O objetivo desta investigação foi perceber os caminhos percorridos pelo discurso dos/as professores/as sobre a sexualidade na instituição escolar. Foram realizadas 18 entrevistas com professoras das disciplinas de Ciências, Educação Física e outras disciplinas que trabalhavam com a sexualidade na sala de aula, ou ainda, que participavam de projetos sobre sexualidade, como o projeto "Saúde e Prevenção nas Escolas". Em muitas entrevistas foram constados aspectos profundamente homofóbicos, marcas reiterativas da exclusão de alunos e alunas gays, lésbicas e transexuais. A partir dos resultados obtidos nessa pesquisa, esse texto se apresenta como um processo de intervenção, ou ainda uma proposta sobre aquilo que podemos aprender com Thomas, Brendon, Bree e Agrado. (CESAR, 2008, p.1-2)

2) "Professores(as), sexualidade e educação sexual: produzindo sujeitos nos contextos do programa afetivo-sexual" (CASTRO, 2008). Nesse artigo, o autor, tem como objetivo

problematizar a formação docente para a abordagem da sexualidade no ambiente escolar. As análises aproximam-se da perspectiva pós-estruturalista, o que significa 
dizer que o interesse é compreender os sujeitos e suas concepções como produto e produtores de discursos e práticas. Além disso, essa ótica permite fomentar questionamentos, socializar questões, ao invés de produzir respostas. Assim, questiona-se a existência de "verdades absolutas" e grandes generalizações. (CASTRO, 2008, p.2)

\title{
3) "Das noções de corpo no ensino de biologia aos dizeres sobre sexualidade" (SILVA;
}

CICILLINI, 2010). Nesse trabalho, as autoras utilizam os saberes da biologia, contextualizando

\begin{abstract}
produções subjetivas quanto é componente das diferenças culturais, comportamentais e históricas; favorece a construção social do conceito de corpo e de sexualidade e do quanto tal construção atravessa espaços e configurações de saber e poder. Neste texto, [...], apresentamos a análise do tema Sexualidade e cultura, incluído no documento Orientação Pedagógica para o Conteúdo Básico Comum Biologia e das noções de corpo relatadas por professoras e alunas(os), respectivamente, em entrevistas e grupos focais. A investigação buscou pelas noções de corpo veiculadas no documento e por professoras(es) e alunas(os), buscando ainda pelos abalos que tais noções provocam nestas pessoas. Um dos abalos trata-se da invisibilidade para os indivíduos das relações entre a ciência e o sociocultural - a ocorrência de um processo de des-subjetivação quanto à afirmação da invenção de corpo biológico que deixa de fora a sexualidade, as emoções e os afetos no espaço da disciplina Biologia. Assim, do ponto de vista metodológico foi realizada uma microanálise dos documentos e uma cartografia das noções de corpo apresentadas, nas entrevistas e grupo focal. (SILVA; CICILLINI, 2010, p.1)
\end{abstract}

Em conclusão às análises, observou-se que, embora seja possível encontrar trabalhos sobre educação intercultural e sexualidade no GT de Didática, as pesquisa relacionadas a questões de metodologias e práticas de ensino sobre sexo e gêneros estão alocadas nos GTs da área temática de gênero, sexualidade e educação.

A discussão sobre os marcadores sociais de gênero e sexualidade no âmbito escolar é de caráter interdisciplinar (BRASIL, 2009). Para cada disciplina, e seu diálogo com outras disciplinas da matriz curricular da educação básica, o debate pode ser abordado de diferentes formas, contemplando os principais aspectos da temática, como, por exemplo, a diferenciação entre sexo e gênero, sexo e sexualidade, bem como a construção relacional da categoria de gênero.

Krasilchik e Marandino (2007, p. 51), “a integração do Ensino de Ciências com outros elementos do currículo, além de levar à análise de suas implicações sociais, dá significado aos conceitos apresentados, aos valores discutidos, e às habilidades necessárias para um trabalho rigoroso e produtivo". 
Dessa forma, acredita-se que as aulas de Ciências, com suas propostas contemporâneas na abordagem do ensino-aprendizagem, na perspectiva sócio-históricocultural, têm inúmeros aspectos que podem ser contemplados para um enfoque seguro e pertinente sobre os marcadores de sexualidade e de gênero. Tal aspecto foi indicado nos PCNs, como tema transversal nos currículos, principalmente em discussões e temas tratados nas áreas contempladas pelas ciências físicas, químicas e biológicas. Entretanto, pouco se tem aferido sobre a inserção do diálogo entre as disciplinas de caráter científico da matriz curricular do ensino básico com essas temáticas.

A análise aqui feita revela, no período de dez anos de apresentação de pesquisas realizadas na área de educação que contemplam a inserção das disciplinas de base científica, a pouca prevalência de trabalhos de pesquisa que realizam a intersecção entre a temática de gênero e sexualidade com as disciplinas de ciências.

Nessa perspectiva, podem-se acionar dois grandes fatores que estão na base desse reflexo: 1) a fragilidade da inserção e a consolidação da temática sobre gênero e sexualidade nas diversas disciplinas da matriz curricular do ensino básico, exemplificadas pelo campo de tensão presenciado com a consolidação do Plano Nacional de Educação (PNE) ${ }^{6}$, além de uma reduzida produção e estudos sobre a temática no ensino de Ciências; 2) a limitada abordagem ou, em muitos casos, a ausência do tema nos cursos de formação de professores, principalmente das áreas das Ciências, para o ensino básico, sugerindo o efeito percebido da desconexão entre as questões da temática com o ensino de Ciências refletida no levantamento numérico do período avaliado.

Para os pesquisadores das práticas escolares no tocante às dimensões de gênero e sexualidade, é consensual a importância da discussão desses aspectos. Os trabalhos de Carvalho (2008), Vianna e Silva (2008) e Jesus et al. (2006) ressaltam que essa importância não está apenas ligada às questões sociais do ensino-aprendizagem sobre a temática debatida, mas também para uma formação humanista do estudante.

No entanto, essa abordagem ainda é deficitária no ensino de Ciências, o que, também para Souza (2008), é um fato que é reforçado pela ausência dessa discussão na formação dos professores das ciências e está intimamente ligado ao caráter da natureza da estrutura

\footnotetext{
${ }^{6}$ O Plano Nacional de Educação (2014-2024) foi sancionado em 25/06/2014, mas retirou os trechos que mencionavam os marcadores sociais de gênero e orientação sexual. $\mathrm{O}$ artigo $2^{\circ}$, era direcionado para a superação das desigualdades educacionais, no qual se destacava uma: "ênfase na promoção da igualdade racial, regional, de gênero e de orientação sexual" após pressão de grupos religiosos fundamentalistas e o sinal de um estado laico frágil.
} 
científica objetiva e pragmática. O caso da Biologia pode ser tomado como exemplo. Nas aulas de genética, principalmente da genética ligada ao sexo (a determinação sexual pela genética), é isolada e apenas condicionada a questão da determinação biológica do sexo. Não se abre espaço para debater a construção social de gênero. Isso denota uma dimensão na formação de professores de Ciências para a educação básica.

Em conclusão, a análise aqui feita reitera a deficiência da abordagem científica das temáticas sobre gênero e sexualidade no contexto das práticas pedagógicas no universo do ensino de Ciências. Tais abordagens nas aulas de Ciências e sua reflexão na pesquisa e nos estudos das práticas científicas na área do ensino das Ciências estão para além da importância cognitiva, tocam no aspecto social - na formação de cientistas e produção do conhecimento -, bem como na formação de uma educação científica e tecnológica agregando a perspectiva de gênero.

\title{
ANALYSIS OF ARTICLES THAT WERE PRESENTED IN ANPED (2004 2013) WITH THE GENDER THEMES AND SEXUALITY IN EDUCATION SCIENCES
}

\begin{abstract}
The theme of gender and sexuality is emerging at the "Annual meetings of the National Association of Graduate Studies and Research in Education" (ANPEd [in portuguese]), specifically in the groups of discussion and proposals: Group 4 - Teaching theme (GT 4) and the Group 23 - Gender, Sexuality and Education themes (GT 23). The purpose of this article is to analyze and understand how these GTs come designing studies that address this theme with focus on teaching of Sciences, the annual meetings of ANPEd, from 2004 to 2013. The methodology involved the identification and analysis of the articles published in the proceedings of the meetings and the survey of all articles posted by GTs 4 and 23, highlighting those that bring educational proposals and analysis on gender and sexuality education regarding the teaching of science.
\end{abstract}

Keywords: Gender and sexuality; Science Teaching; ANPEd 


\section{ANÁLISIS DE LOS ARTÍCULOS QUE SE PRESENTARON EN ANPED (2004 2013) CON LOS TEMAS DE GÉNERO Y SEXUALIDAD EN LA EDUCACIÓN DE LAS CIENCIAS}

\section{Resumen}

El tema del género y la sexualidad está emergiendo en las reuniones anuales de la Asociación Nacional de Estudios de Posgrado e Investigación en Educación (ANPEd), concretamente en el Grupo de Trabajo 4 - Enseñanza (GT 4) y el Grupo de Trabajo 23 - Género, Sexualidad y Educación (GT 23). El propósito de este artículo es analizar y comprender cómo estos GTs vienen diseñar estudios que abordan este tema se centró en la enseñanza de las ciencias, las reuniones anuales de ANPEd, de 2004 a 2013. La metodología involucró la identificación y análisis de los trabajos publicados en los anales de las reuniones y la encuesta de todos los artículos publicados por GTs 4:23, destacando los que traen propuestas educativas y análisis sobre la educación de género y la sexualidad en relación con la enseñanza de la ciencia. Llegamos a la conclusión de nuestro análisis un enfoque científico reducido a cuestiones de género y sexualidad en el contexto de las prácticas de enseñanza en la enseñanza de la ciencia en el universo.

Palabras clave: Género Y Sexualidade; Enseñanza De Las Ciencias; ANPED

\section{REFERÊNCIAS}

BARREIROS, Cláudia Hernandez. Investigar a ação docente frente às diferenças, operando com a noção de jurisprudência pedagógica”. REUNIÃO ANUAL DA ANPEd, 30ª , 2007, Caxambu. ANPEd: 30 Anos De Pesquisa E Compromisso Social. Disponível em: < http://30reuniao.ANPEd.org.br/>. Acesso em: 29 set. 2015.

BORILLO, Daniel. Homofobia: história e crítica de um preconceito. Belo Horizonte: Autêntica, 2010.

BRASIL. Gênero e Diversidade na Escola: Formação de professores/as em Gênero.Orientação Sexual e Relações Étnico-Raciais. Rio de Janeiro: CEPESC; Brasília, SPM,2009.

BRASIL. Ministério da Educação. Secretaria de Educação Continuada, Alfabetização e Diversidade (SECAD). Cadernos SECAD 4 - Gênero e Diversidade Sexual na Escola: reconhecer diferenças e superar preconceitos. Brasília: MEC, 2007. Disponível em:<http://portaldoprofessor.mec.gov.br/storage/materiais/0000015505.pdf>. Acesso em: 20 jun. 2015 . 
CARVALHO, Maria Eulina P. de. Construção e desconstrução de gênero no cotidiano da educação infantil: alguns achados de pesquisa. In: REUNIÃO ANUAL DA ANPED, 31 ., 2008, Caxambu. Grupo de Trabalho 23. Caxambu: [s.e.], 2008. Disponível em: $<$ http://www.anped.org.br/reunioes/31ra/5trabalhos_encomendados/trabalho\%20encomendad o\%20-\%20gt 23\%20-\%20maria\%20eulina\%20pessoa\%20de\%20carva.pdf >. Acesso em: 20 de Jun. 2015.

CARVALHO, Marília Pinto de. Gênero: pra que serve esse conceito na prática pedagógica?. In: SOARES, Leôncio Soares et al. Convergências e tensões no campo da formação e do trabalho docente. Belo Horizonte: Autêntica, 2010.

CASTRO, Roney Polato de. Professores (as), sexualidade e educação sexual: produzindo sujeitos nos contextos do programa afetivo-sexual. REUNIÃO ANUAL DA ANPEd, 31 a, 2008, Caxambu. Constituição Brasileira, Direitos Humanos e Educação. Disponível em: < http://36reuniao.ANPEd.org.br/>. Acesso em: 29 de Set. 2015.

CÉSAR, Maria Rita de Assis. Quatro intervenções de uma pedagogia Queer. REUNIÃO ANUAL DA ANPEd, 31ª , 2008, Caxambu. Constituição Brasileira, Direitos Humanos e Educação. Disponível em: < http://36reuniao.ANPEd.org.br/>. Acesso em: 29 set. 2015.

COLVERO, Kaé Stoll. O reconhecimento para além da igualdade: subsídios para uma educação intercultural. REUNIÃO ANUAL DA ANPEd, 36, 2013, Goiânia. Sistema Nacional de Educação e Participação Popular: Desafios para as Políticas Educacionais. Disponível em: < http://36reuniao.ANPEd.org.br/>. Acesso em: 29 set. 2015.

FRANCO, M. A. S.; PIMENTA, S. G.; ALMEIDA, M. I.; FUSARI, J. C. A construção da didática no gt Didática - análise de seus referenciais. Revista Brasileira de Educação (Impresso), v. 18, p. 143-162, 2013. Disponível em:

http://www.scielo.br/pdf/rbedu/v18n52/09.pdf>. Acesso em: 29 set. 2015.

JESUS, Beto de et al. Diversidade sexual na escola: uma metodologia de trabalho com adolescentes e jovens. São Paulo: Ecos, 2006.

KRASILCHIK, M.; MARANDINO, M. Ensino de Ciências e cidadania. $2^{\text {a }}$ ed. São Paulo: Moderna, 2007.

LIMA E SOUZA, Ângela. M. F.; Ensino de Ciências: onde está o gênero?. Revista da FACED (Impresso), v. 13, p. 149-160, 2009.

SAMBUGARI, Márcia Regina do Nascimento. “Aponte o lápis, cole os bilhetes"... 'Sim, professora!': a socialização entre alunos estagiários e professoras em exercícios”. REUNIÃO ANUAL DA ANPEd, 35a , 2012, Porto de Galinhas. Educação, Cultura, Pesquisa e Projetos de Desenvolvimento: o Brasil do Século XXI. Disponível em: < http://35reuniao.ANPEd.org.br/>. Acesso em: 29 de Set. 2015. 
SILVA E. P. Q.; CICILLINI, G. A. Das noções de corpo no ensino de biologia aos dizeres sobre sexualidade. REUNIÃO ANUAL DA ANPEd, 33a , 2010, Caxambu. "Educação no Brasil: O Balanço de uma Década. Disponível em: < http://35reuniao.ANPEd.org.br/>. Acesso em: 29 de Set. 2015.

SOARES, A. G. Presenças, silêncios e ausências sobre gênero e diversidade sexual no âmbito do currículo de dois cursos da educação profissional. 170 f. 2012. Dissertação (Mestrado em Educação Tecnológica). CEFET/MG. Belo Horizonte, 2012. Disponível em: < http://www.files.scire.net.br/atrio/cefet-mgppget_upl/THESIS/180/alexandre_gomes_soares.pdf> Acesso em: 29 de Set. 2015.

VIANNA, C.P.; UNBEHAUM, S. Gênero na educação básica: quem se importa?: uma análise de documentos de políticas públicas no Brasil. Educação \& Sociedade, Campinas, v. 28, n. 95, p. 407-428, maio/ago. 2006.

VIANNA, C. P.; SILVA, C. R.. Contribuições para a análise da educação escolar. Revista Educação. (Grandes Temas). Editora Segmento. São Paulo 2008.

WEEKS, Jeffrey. Sexualidade, militância e direitos humanos. Revista do Instituto Humanitas Unisinos, São Leopoldo.2009. Disponível em: < http://www.ihu.unisinos.br/noticias/noticiasanteriores/20411-jeffrey-weeks-sexualidade-militancia-e-direitoshumanos.unisinos.br/index.php?option=com_content\&view=article\&id=470\&secao=199>.Ac esso em: 10 de Mai. 2015.

Data de recebimento: 24/11/2015

Data de aceite: 29/02/2016 